\title{
Inhibitory Action of Ficus carica Extracts on Aluminium Corrosion in Acidic Medium
}

\author{
A. I. ONEN ${ }^{*}$, J. T. BARMINAS ${ }^{\mathrm{b}}$ and J. JACOB ${ }^{\mathrm{a}}$ \\ ${ }^{a}$ Department of Chemistry, Adamawa State University, \\ P.M.B 25, Mubi, Adamawa State, Nigeria \\ ${ }^{\mathrm{b}}$ Department of Chemistry, Modibbo Adama University of Technology, \\ Yola Adamawa State, Nigeria \\ alfredonen@yahoo.com
}

Received 18 February 2013 / Accepted 19 March 2013

\begin{abstract}
Inhibition of aluminium corrosion in $\mathrm{HCl}$ solutions by Ficus carica leaf extract and was studied using weight loss measurements at 303, 313, 323 and $333 \mathrm{~K}$. The adsorption of the inhibitor on aluminium surface follows Frumkin and Langmuir adsorption isotherms. The effect of temperature indicated that the corrosion rate and inhibition efficiency are temperature dependent in the range 303-333 K. Increase in temperature increased the corrosion rate but decreased the inhibition efficiency in the absence and presence of the inhibitor. The kinetic data obtained indicates that the adsorption follows a first order type of reaction. Physisorption mechanism has been proposed for the inhibitor. The presence of alkaloids, glycosides, saponins and tannins (having $-\mathrm{C}=\mathrm{O}, \mathrm{C}-\mathrm{OH}, \mathrm{C}=\mathrm{C}, \mathrm{OH}-\mathrm{CH}_{3}$, etc. groups) was found to have contributed greatly to the inhibition process by interacting with the aluminium surface.
\end{abstract}

Keywords: Ficus carica extract, Weight loss method, Corrosion inhibitor, Frumkin isotherm

\section{Introduction}

Aluminium is one of the most important and widely used metals in the transport, construction and packaging and electrical sectors. It is pertinent to note that aluminium is prone to corrosion due to its negative standard potential of $-1.66 \mathrm{~V}$. The susceptibility of $\mathrm{Al}$ to attack is observed in oil well acidizing, pickling, cleaning and descaling operations where the metal is exposed to hydrochloric or sulphuric acid once the protective oxide layer is destroyed.

Over the years, it has been observed that these valuable metals (e.g. Al) and alloys (e.g. Brass) deteriorate due to corrosion in different environments (acidic or alkaline). Different organisations and industries therefore spend huge sum of money in combating corrosion of their engine parts, pipe lines etc. The need to research into the field of corrosion inhibition using less expensive, environmentally friendly inhibitors has therefore becomes very desirable. 
Different synthetic organic inhibitors are used for Al alloys, other metals and alloys in various aggressive media ${ }^{1}$. Most of these organic inhibitors are nitrogen, oxygen or sulphur containing compounds. Inorganic compounds and their derivatives have also been reported as inhibitors for metals/alloys in aqueous solutions $\mathrm{s}^{2-5}$. The use of dyes (anthraquinoid, azo, cyanine, heterocyclic, xanthenes etc) as corrosion inhibitor inhibitors of aluminium, mild steel, $\mathrm{Zn}$ etc. in acid corrodent have been reported by several workers ${ }^{6-11}$.

These synthetic organic, inorganic, dyes etc. compounds used as corrosion inhibitors are expensive, toxic and hazardous to health. It has become important therefore, to source for cheap, non-hazardous and environmentally friendly inhibitors for the protection of metals/alloys against corrosion. Many authors ${ }^{12-16}$ have investigated the possible substitute for these costly, toxic and environmentally non-friendly chemicals used as corrosion inhibitors for metals/alloys in acid/alkaline media from naturally occurring substances of plant origin.

Ficus carica is a small tree native to South West Asia. This edible plant is widely grown for its fruit and is commercially produced in the United States of America. This tree is also found in some parts of Northern Nigeria with Adamawa State inclusive. Several therapeutic effects such as hypoglycaemia ${ }^{17}$, hypotriglyceridemia and hyperchole-sterolemia ${ }^{18}$ have been reported for different parts of Ficus carica. The presence of alkaloids, flavonoids and tannins in Ficus carica leaf extracts has prompted the need for its selection as corrosion inhibitor. This is because in addition to heteroatom in alkaloids and flavonoids which are the major adsorption centres, tannins exhibit a dual corrosion retarding action via the formation of a protective oxide film and tannate at the anodic sites of the corroded surface ${ }^{19}$.

In the present investigation, the inhibitive effect has been evaluated of methanolic leaf extracts of Ficus carica and has worked as green inhibitor, which is non-toxic and biodegradable. The investigation is carried out using weight loss method to study the corrosion inhibition potential of Ficus carica at 303 K, 313 K, 323 K and 333 K respectively.

\section{Experimental}

The aluminium sheets used for this study and purity of $99.8 \%$ were obtained from Mubi in Adamawa State of Nigeria. Each of these sheets was $9.0 \times 10^{-3} \mathrm{~mm}$ thick. They were mechanically press cut into $5.0 \times 4.0 \mathrm{~cm}$ (area of $20 \mathrm{~cm}^{2}$ ) coupons and were used without further polishing. These coupons were however degreased in ethanol, dried in propanone and stored in moisture free desiccators before corrosion studies commenced.

Fresh leaves of Ficus carica were collected and air dried for 10-14 days in a shade (to enrich the active ingredients in them by reducing their moisture content) and then pulverized into powdery form. $200 \mathrm{mg}$ of the fine powdery sample was dissolved in $400 \mathrm{~mL}$ methanol in a round-bottomed flask and was covered with stopper and left for $24 \mathrm{~h}$. The resulting paste was the decanted and filtered. The leaf extract was however concentrated on a rotary evaporator (RYC-R-205D) at $45^{\circ} \mathrm{C}$. Extract concentration of $10^{1}$ to $10^{2} \mathrm{mg} / \mathrm{L}(10,30,50,70$ and $100 \mathrm{mg} / \mathrm{L}$ ) obtained by serial dilution was employed for the study. A concentration of 0.1-0.5 $\mathrm{M} \mathrm{HCl}$ was also prepared and used as corrodent.

\section{Weight loss measurements}

Five $250 \mathrm{~mL}$ beakers separately containing $0.1,0.2,0.3,0.4$ and $0.5 \mathrm{M} \mathrm{HCl}$ solutions were placed in a thermostated water bath maintained at 303, 313, 323 and 333K. Previously weighed aluminium coupons were immersed in each beaker with the aid of threads (suspended 
through a hole drilled at one end). These coupons were retrieved at $24 \mathrm{~h}$ intervals progressively for 168 hours ( 7 days) and washed several times in $20 \% \mathrm{NaOH}$ containing $200 \mathrm{mg} / \mathrm{L}$ of $\mathrm{Zn}$ dust, cleaned, dried in propanone and reweighed.

The difference in mass $(\mathrm{mg})$ of the coupons was recorded as the weight loss of $\mathrm{Al}$ in each case. Each of the reported readings is an average of seven experimental readings recorded to the nearest $0.0001 \mathrm{mg}$ on OHAU SCOUT 11 digital electronic balance (NJ 07058 USA).

The second part of the study involves measurements of weight loss after introduction of the inhibitor (Ficus carica) in five sets of $250 \mathrm{~mL}$ beakers maintained at 303, 313, 323 and $333 K$. Previously weighed Al coupons were introduced into all the beakers containing different concentrations of the inhibitor. Each coupon was retrieved from the inhibitor solutions at $24 \mathrm{~h}$ intervals for a period of 168 hours, washed, dried and reweighed. The difference in mass recorded for a period of 168 hours (7 days) was again taken as the weight loss (mg). The inhibition efficiency (\% I), surface coverage $(\theta)$ and corrosion rate for $\mathrm{Al}$ was calculated using the equations.

$$
\begin{aligned}
\% \mathrm{I} & =1-\left(\mathrm{W}_{1} / \mathrm{W}_{2}\right) \times 100 \\
\theta & =1-\mathrm{W}_{1} / \mathrm{W}_{2} \\
\mathrm{CR}\left(\mathrm{gh}^{-1} \mathrm{~cm}^{-2}\right) & =\text { W/DAT }
\end{aligned}
$$

Where $\mathrm{W}_{1}$ and $\mathrm{W}_{2}$ are the weight losses $(\mathrm{mg})$ for $\mathrm{Al}$ in the absence and presence of the inhibitors in $\mathrm{HCl}$ solution, $\theta$ is the degree of surface coverage of the inhibitors, $\mathrm{D}$ is the density of $\mathrm{Al}, \mathrm{A}$ is the area of aluminium coupon $\left(\right.$ in $\mathrm{cm}^{2}$ ), $\mathrm{T}$ is the period of immersion (in hours) and $\mathrm{W}$ is the weight loss of aluminium ${ }^{20}$ after time, t. All the measurements were performed in triplicate and the mean value was recorded.

\section{Results and Discussion}

\section{Effect of corrodent concentration and temperature on aluminium corrosion}

Figure 1 and Table 1 show the variation of weight loss with time (days) for Al corrosion in $\mathrm{HCl}$ at $303 \mathrm{~K}$ without Ficus carica. It was observed that the weight loss (mg) of aluminium increased with increasing acid concentration and temperature.

Similar trend was observed at $313 \mathrm{~K} 323 \mathrm{~K}$ and $333 \mathrm{~K}$ respectively, but with higher values of weight loss. This could be attributed to an increase in the rate of ionization and diffusion of active ions in the corrosion process. Increase in temperature favours the formation of aluminium(III) chloride with the $\mathrm{Cl}^{-}$ions which is also corrosive to aluminium.

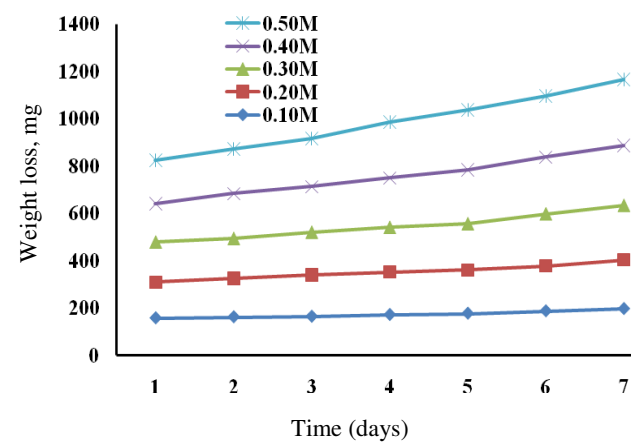

Figure 1. Variation of weight loss with time (days) for aluminium coupons corrosion in various concentrations of $\mathrm{HCl}$ at $303 \mathrm{~K}$ 
Table 1. Corrosion parameters for aluminium corrosion in $0.50 \mathrm{M} \mathrm{HCl}$ containing Ficus carica from weight loss measurement

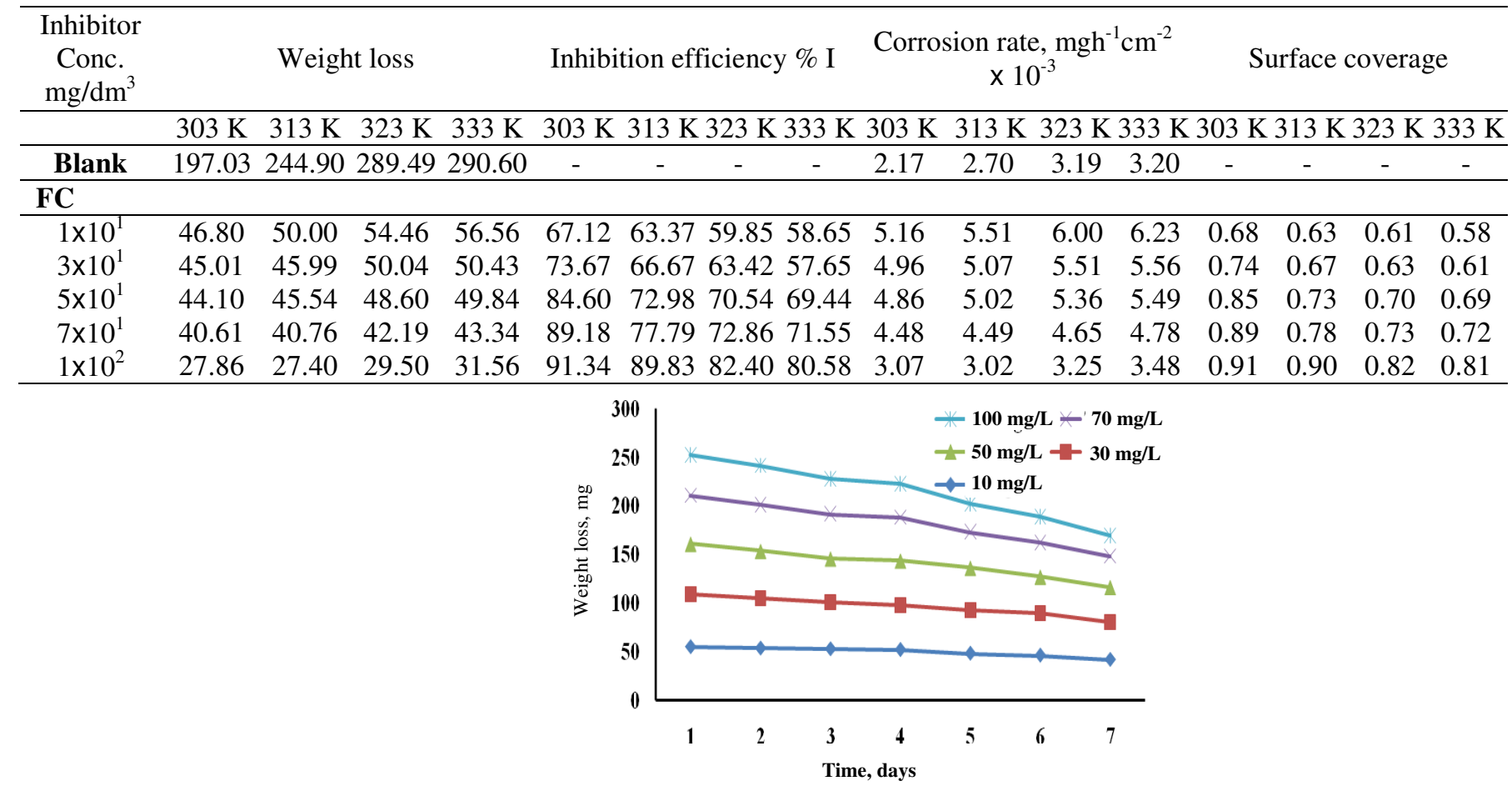

Figure 2. Variation of weight loss with time for aluminium corrosion in $0.5 \mathrm{M} \mathrm{HCl}$ containing various concentrations of $\mathrm{FC}$ at $303 \mathrm{~K}$ 


\section{Effect of inhibitor (Ficus carica) concentration on aluminium corrosion}

Figure 2 shows the variation of weight loss with time (days) for $\mathrm{Al}$ corrosion in $0.5 \mathrm{M} \mathrm{HCl}$ with various concentrations of Ficus carica at $303 \mathrm{~K}$. The graph reveals that the weight loss was lowest at $100 \mathrm{mg} / \mathrm{L}$ (highest concentration of inhibitor studied) on aluminium when compared to other concentrations. This indicates that Ficus carica actually inhibited the corrosion of aluminium with inhibition increasing with inhibitor concentration and decreases with increase in temperature.

With the addition of the inhibitor, (Ficus carica) corrosion rates decreased while the inhibition efficiency and surface coverage increased significantly with increasing concentration. However, inhibition efficiency and surface coverage decrease with increasing temperature (303-333 K) (Table 1) with a maximum at $91.34 \%, 89.83 \%, 82.40 \%$ and $80.58 \%$ at $303,313,323$ and $333 \mathrm{~K}$ respectively. This shows that the inhibitor function effectively at lower temperature which suggest physisorption. This assertion agrees with the findings of Ebenso et al..$^{5}$ and Onen and Nwufo ${ }^{21}$. The behaviour of the inhibitor at $303 \mathrm{~K}$ may be attributed to the adsorption of the inhibitor up to $313 \mathrm{~K}$ and after that further increase in temperature brings about desorption of the inhibitor; Ficus carica under study.

\section{Adsorption characteristics of ficus carica}

From Table 1 and Figure 3, it is evident that the inhibition efficiency and surface coverage increase with increasing inhibitor concentration and decrease with increasing temperature, from 303-333 K. This is suggestive of physical adsorption (physisorption) mechanism. This assertion is in good agreement with observations earlier made by ${ }^{5,11}$. Figure 3 also shows that the isotherm of higher temperature $(333 \mathrm{~K})$ is under that of lower temperature $(303 \mathrm{~K})$; this further confirms physical adsorption for the inhibition process. The high surface coverage data observed at high inhibitor concentration is due to very strong interactions between the adsorbed species. The surface coverage data also implies that the adsorption of Ficus carica at the aluminium interface may be due to electrostatic force between the atoms on the metal surface and the adsorbates (inhibitor molecules). This confirms to observations earlier published by ${ }^{12}$.

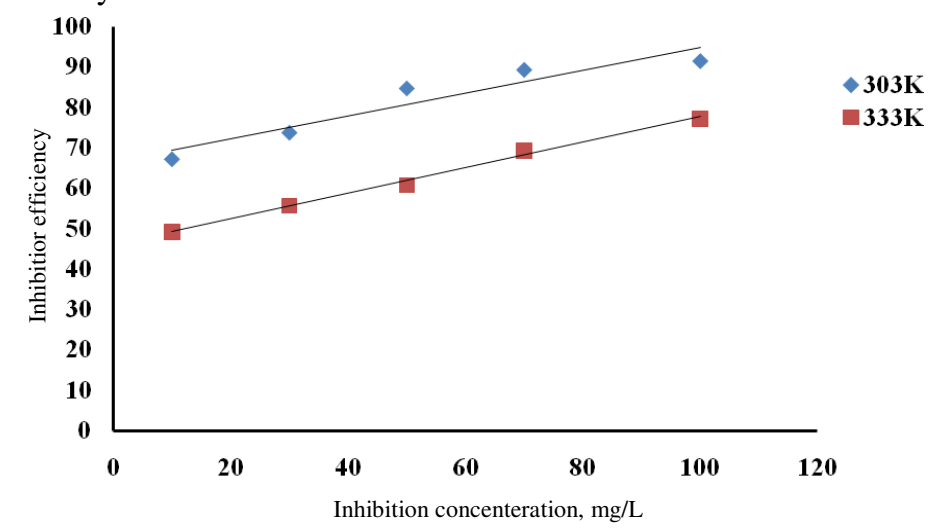

Figure 3. Plot of inhibition efficiency (\% $\mathrm{I}$ ) versus inhibitor (FC) concentration for aluminium at $303 \mathrm{~K}$ and $333 \mathrm{~K}$

To establish the extent of adsorption of inhibitor molecules on aluminium surface, some adsorption isotherms were plotted. The linear plot obtained from the graphs of ' $\mathrm{C}$ ' $/ \theta$ against ' $\mathrm{C}$ ' at 303 and $333 \mathrm{~K}$ (Figure 4) shows that the experimental data obtained within the 
temperature range fits Langmuir adsorption isotherm. In a similar way, a plot of surface coverage $(\theta)$ versus inhibitor concentration (' $\mathrm{C}$ ') gave a straight line indicating that Frumkin isotherm is obeyed. This confirms that corrosion inhibition is often due to formation and maintenance of a thin protective layer on the metal surface. This is in agreement with the findings of ${ }^{5}$.

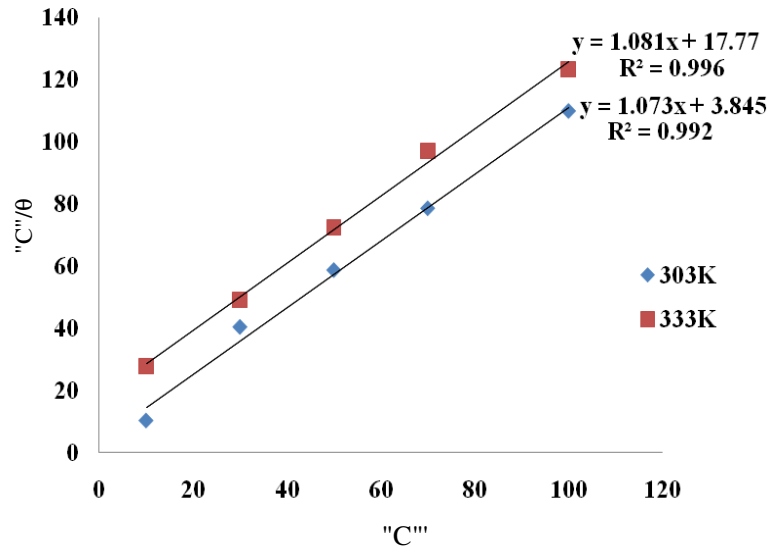

Figure 4. Langmuir isotherm plotted as "C"/ $\theta$ versus " $\mathrm{C}$ " for aluminium corrosion in $0.5 \mathrm{M}$ $\mathrm{HCl}$ containing different concentrations of $\mathrm{FC}$ at $303 \mathrm{~K}$ and $333 \mathrm{~K}$

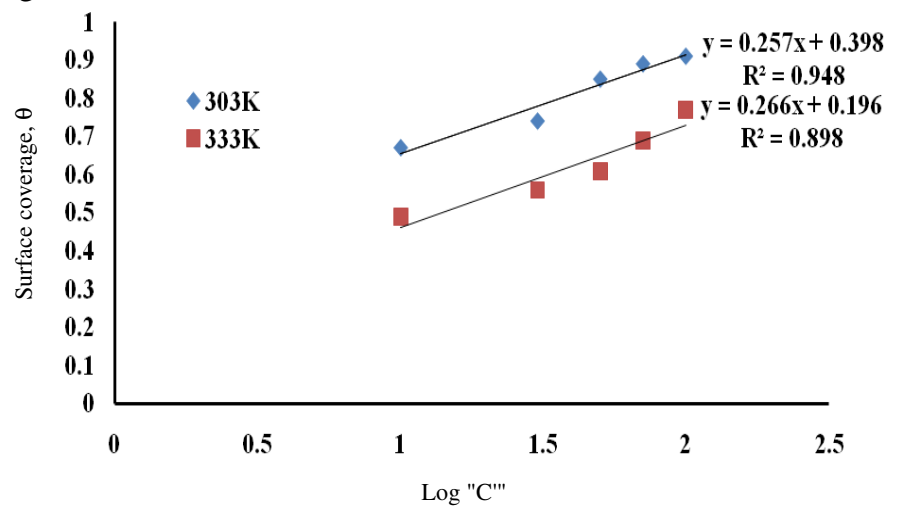

Figure 5. Frumkin adsorption isotherm plotted as " $\theta$ " versus $\log$ " $\mathrm{C}$ " for aluminium corrosion in $0.5 \mathrm{M} \mathrm{HCl}$ containing various concentrations of Ficus carica at $303 \mathrm{~K}$ and $333 \mathrm{~K}$.

\section{Inhibition mechanism}

Tables 2 show the calculated values of rate constant $(\mathrm{k})$, half life, $\mathrm{t}_{1 / 2}$ and activation energy, $\mathrm{E}_{\mathrm{a}}$. The average values of activation energy, $E_{\mathrm{a}}$ for the extracts studied (13.87 and $\left.14.05 \mathrm{kJmol}^{-1}\right)$ are lower than $40.0 \mathrm{kJmol}^{-1}$ indicating that the compound is physically adsorbed on $\mathrm{Al}$ surface. Physical adsorption requires that the average $\mathrm{E}_{\mathrm{a}}$ to be $40.0 \mathrm{kJmol}^{-1}$ and the inhibition efficiency should increase at lower temperatures. This agrees with an earlier report ${ }^{11}$.

\section{Kinetic consideration}

The activation energy values presented in Tables 2 were obtained from the plots of the logarithm of rate constant $(\mathrm{k})$ against the inverse of temperatures understudy $(303,313,323$ and $333 \mathrm{~K}$ ). The slope of the line multiplied by the ideal gas constant $\mathrm{R}$ gives the activation energy, $E_{a}$. The activation energy of the inhibited solution decreases by increasing the 
concentration of Ficus carica. This finding indicates that this inhibitor retards the corrosion of aluminium in the studied media $(\mathrm{HCl})$. The values of rate constants, $\mathrm{k}$ also recorded in Tables 2 were obtained from plots of $\log \mathrm{W}_{\mathrm{L}}$ versus time (days) in $\mathrm{HCl}$ solutions (plots not shown) while the half life, $\mathrm{t}_{1 / 2}$ were determined from the expression:

$$
\mathrm{t}_{1 / 2}=0.694 / \mathrm{k}
$$

Table 2. Some kinetic data for aluminium corrosion in $0.5 \mathrm{M} \mathrm{HCl}$ containing Ficus carica from weight loss measurement

\begin{tabular}{ccccccc}
\hline $\begin{array}{c}\text { Inhibitor } \\
\text { concentration } \\
\mathrm{mg} / \mathrm{L}\end{array}$ & $\begin{array}{c}\text { Rate constant, } \\
\mathrm{k} \mathrm{s}^{-1}\end{array}$ & \multicolumn{2}{c}{$\begin{array}{c}\text { Half-life, } \mathrm{t}_{1 / 2} \\
\mathrm{~s}\end{array}$} & \multicolumn{2}{c}{$\begin{array}{c}\text { Activation energy, } \mathrm{E}_{\mathrm{a}} \\
\mathrm{kJmol}^{-1}\end{array}$} \\
\hline Blank & $303-313 \mathrm{~K}$ & $323-333 \mathrm{~K}$ & $303-313 \mathrm{~K}$ & $323-333 \mathrm{~K}$ & $303-313 \mathrm{~K}$ & $323-333 \mathrm{~K}$ \\
$\mathrm{FC}$ & & & & & & \\
$1 \times 10^{1}$ & $2.63 \times 10^{-2}$ & $1.82 \times 10^{-2}$ & $2.63 \times 10^{1}$ & $3.81 \times 10^{1}$ & 14.31 & 14.51 \\
$3 \times 10^{1}$ & $2.68 \times 10^{-2}$ & $2.42 \times 10^{-2}$ & $2.59 \times 10^{1}$ & $3.12 \times 10^{1}$ & 13.95 & 14.38 \\
$5 \times 10^{1}$ & $2.53 \times 10^{-2}$ & $2.22 \times 10^{-2}$ & $2.74 \times 10^{1}$ & $3.12 \times 10^{1}$ & 13.81 & 13.77 \\
$7 \times 10^{1}$ & $1.93 \times 10^{-2}$ & $2.57 \times 10^{-2}$ & $3.59 \times 10^{1}$ & $2.70 \times 10^{1}$ & 13.78 & 13.77 \\
$1 \times 10^{2}$ & $4.47 \times 10^{-2}$ & $1.92 \times 10^{-2}$ & $1.55 \times 10^{1}$ & $3.60 \times 10^{1}$ & 13.56 & 13.58 \\
Mean & & & & & 13.87 & 14.05 \\
\hline
\end{tabular}

The observed linearity from the plots reveals first order kinetics for the inhibition process. The rate constant, $\mathrm{k}$ decreases with increase in concentration of all the inhibitors while the half life increases with increasing inhibitors concentration. These observations further confirm the fact that the inhibition process follows first order kinetics.

\section{Conclusion}

The study shows that the inhibitor (FC) investigated inhibits the acid corrosion of aluminium with inhibition efficiency (\% I) increasing with concentration but decreasing with temperature. On the basis of $\mathrm{E}_{\mathrm{a}}$ values, $\mathrm{FC}$ obeys the mechanism of physisorption, as seen from the experimentally observed increase in inhibition efficiency $(\% \mathrm{I})$ with decrease in temperature. The adsorption of Ficus carica on aluminium surface in $0.5 \mathrm{M} \mathrm{HCl}$ obeyed Frumkin and Langmuir adsorption isotherms.

\section{References}

1. El Naggar M M, Corros Sci., 2007, 49(5), 2226.

2. Ibok U J, Ekpe U J, Abakede O U and Offiong O E, Trop J Appl Sci., 1993, 3, 54.

3. Ekpe U J, Ibok U J, Ita B I, Offiong O E and Ebenso E E, Mater Chem Phy., 1995, 48, 87.

4. Ebenso E E, Nig Corros J., 1998, 1(1), 29.

5. Ebenso E E, Ekpe U J, Ita B I, Offiong O E and Ibok U J, Mater Chem Phys., 1999, 60, 79 .

6. Ita B I and Edem C A, Glob J Pure Appl Sci., 2000, 60(20), 239.

7. Ebenso E E, Mater Chem Phys., 2003, 79(1), 58.

8. Ebenso E E, Okafor P C, Ibok U J, Ekpe U J and Onuchukwu A I, J Chem Soc Nig., 2004, 29(1), 15-25.

9. Oguzie E E, Ogukwe B N, Okolue B N, Onuoha G N and Onuchukwu A I, Proc Chem Soc Nig., 2004, 59-62. 
10. Onen A I, Nig J polym Sci Tech., 2006, 5(1). 357.

11. Onen A I, Maitera O N, Jacob J and Ebenso E E, Int J Electrochem Sci., 2011, 6, 2884.

12. Ekpe U J, Ebenso E E, and Ibok U J, J West African Sci Asso., 1994, 37, 13-16.

13. Ekpe U J, Ita B I and Bassey A E, Glob J Pure Appl Sci., 1997, 3, 49-59.

14. Onen A I, Nig J Appl Sci., 2004, 22, 174.

15. Onen A I, Nwufo B T and Ebenso E E, J Chem., 2011, 8(4), 1708-1713.

16. Sribharathy V, Rajendran S and Sathiyabama J, Chem Sci Trans., 2013, 2(1), 315-321.

17. Serraclara A, Hawkins F, Perez C, Dominguez E, Campillo J E and Torres M D, Diabetic Resources Clin Prac., 1998, 39(1), 19-22.

18. Perez C, Canal J R, Campillo J E, Romero A and Torres M D, Acta Phys Hung., 1999, 86, 57-68.

19. Abiola O K, Oforka N C, Nwinuka N M and Ebenso E E, Anti Corros Methods Mater., 2007, 54, 219.

20. Eddy N O, Ibok U J, Ebenso E E, El Nemr A, El Sayed H and El Ashry E, J Mol Model., 2009, 15, 1085-1092.

21. Onen A I and Nwufo B T, Indian Bull Pure Appl Sci., 2007, 26C(1), 1. 